\title{
Anaphoric Dependence and Logical Form
}

\author{
Manuel García-Carpintero \\ University of Barcelona
}

\begin{abstract}
In the core chapters 4-6, Iacona (2018) argues against the "Uniqueness Thesis" (UT), stating that "there is a unique notion of logical form that fulfils both the logical role and the semantic role" (39), where the former "concerns the formal explanation of logical properties and logical relations, such as validity or contradiction" (37), and the latter "concerns the formulation of a compositional theory of meaning" (ibid.). He argues for this on the basis of relations of coreference among referential expressions, names and indexicals. From what I take to be a fundamental agreement on most relevant issues, here I will nonetheless press him to clarify the notions of intrinsicness and the logical and semantic role of logical form on which he relies.
\end{abstract}

\section{Keywords}

Analyticity, anaphora, coreference, logical validity, semantic content.

\section{Introduction}

Iacona (2018) argues in the core chapters 4-6 against the "Uniqueness Thesis" (UT), stating that "there is a unique notion of logical form that fulfils both the logical role and the semantic role" (39), where the former concerns "the formal explanation of logical properties and logical relations, such as validity or contradiction" (37), and the latter "the formulation of a compositional theory of meaning" (ibid.). UT is supposed to be motivated by another claim, "intrinsicalism" (I), the view that "there is a unique intrinsicalist notion of logical form that fulfils both the logical role and the semantic role" (40). An intrinsicalist notion, he further tells us, is one that "assumes that logical form is determined by intrinsic properties of sentences" 
(40); where "intrinsic properties of $s[\ldots]$ are invariant properties that $s$ possesses independently of how it is used in this or that context, whereas others are extrinsic properties of $s$, in that they may depend on how $s$ is used in this or that context" (37). He argues that there are two notions of logical form, a "syntactic" one that accords with (I) and is adequate to play the semantic role, and a different, "semantic" one that is at odds with (I) and is the one that fulfils the logical role. In different passages, though, Iacona allows that some intrinsicalist views deploy a "semantic" notion of logical form; he mentions among them (45) the one I myself have advanced (GarcíaCarpintero 1993, 2003, 2004): "any view according to which logical form is determined by intrinsic properties of sentences - syntactic or semantic - may be classified as a version of intrinsicalism" (46).

Iacona's arguments for this claim depend on what I take to be logical properties of relations of de jure (or internal) coreference (Fine 2007, Schroeter 2012), involving context-dependent expressions like indexicals and proper names, a topic that I have discussed in previous work (García-Carpintero 2004, 2014). The way Iacona appears to understand these issues (but, as the following pages will make clear, I am not sure I have understood it) suggests to me that he agrees to a large extent with Fodor (2008), Fiengo and May (2006), Heck (2012), Sainsbury and Tye (2012), Pryor (2017), and Schroeter and Schroeter (2016), who support deflationary, "syntactic" accounts of de jure coreference, in terms of a (syntactic) notion of logical form. As Sainsbury and Tye (2012: 87) put it, "data are to be explained by sameness and differences in vehicles of content, rather than sameness and differences in content". In contrast, Fine (2007) and Recanati $(2013,2016)$ offer a (by some measures: see below) semantic account, and I $(2004,2014)$ have argued for another one, aiming at sufficiently capturing the "transparency" claims that Iacona also rejects $(\S \S 6.4,6.6)$. I'll proceed as follows: I will start by outlining my own account of these matters, as developed elsewhere $(\S 2)$; then I'll use that background to raise some concerns. As I have already indicated, my aim is mostly clarificatory; I am really unsure whether we disagree. 


\section{De jure coreference and logical form}

Frege posed his well-known problem of cognitive significance (which is behind the issues I want to raise) for identity sentences, but, as many commentators have pointed out, ${ }^{1}$ this is done just for convenience. Sentences of the forms $a=a$ and $a=b$ have different semantically significant properties, even when both are true: the former are a priori (in fact - and in my view this is what is truly semantically significant - a priori because analytic) while the latter are not. By "semantically significant" I mean that they are a crucial piece of data for a semantic theory to explain, and thus crucial tests for the adequacy of semantic theories (cf. Yalcin 2014). But the same applies to $a$ is $F$ and $b$ is $F$, even when $a$ and $b$ co-refer: the former logically (and hence, in my view, analytically, which again is what I take to be a semantically significant feature) follows from $a$ is $F$, while the latter does not. Like Iacona, I will have in mind the more general issue, but I'll focus mostly on identity sentences for convenience.

On a narrowly syntactic version of (I), the form of true identity sentences is determined by orthographic shape; on this view, sameness of expression is being understood in terms of sameness of form (plus perhaps sameness of referent). Let us call this the narrowly syntactic ('NS') characterization of form. As Iacona notices, given NS there are no significant differences between $a=a$ and $a=b$; for, as Kripke's (1979) 'Paderewski' example illustrates, a true identity of the first form might require contextual information to establish it as much as one of the second (77-8, 82-3).

Let me present in contrast my own alternative view on logical form, which appeals to what I will call the internal coreference ('IC') criterion. Let us assume that an argument expressed in a natural language is logically valid if it has a valid correct formalization in a formal language (which at least agrees in wording with the proposal Iacona's relies on, 60), and consider the English sentence (1):

(1) Hesperus equals itself.

Is formula (2) a correct first-order formalization of it?

(2) $\mathrm{a}=\mathrm{a}$

${ }^{1}$ Cf., e.g., Heck 2012: 155-6, and references there. 
By allowing it to be so, we can count (1) as logically valid, in that there is a correct formalization of it in first-order logic with identity that is formally valid. This looks like an intuitively correct result; however, under NS the answer should be negative. It is a syntactic feature of (2) that it includes expressions of the same type at two different syntactic positions in the sentence's structure. In that respect, it differs from (3):

(3) $a=b$

(3), on the other hand, would count as a correct formalization of, say, (4) below, which is not logically valid because a correct formalization such as (3) is not first-order valid, and no alternative correct first-order-valid formalization appears to exist (against what Iacona suggests, 78-80: we'll come back to this):

(4) Hesperus equals Phosphorus.

The more general problem for NS now appears manifest: given it, (3) appears to provide the correct formalization of (1), in that the relevant traits of (1) for that criterion are those that it shares with (4), namely, it features co-referential expressions of different types occupying the subject- and object-positions of the verb 'equals'. Thus, given NS, (1) does not share its logical form with the (one sentence) arguments correctly formalized by (2), and therefore should not count as logically valid. What this suggests is that NS misses what is really relevant to determining logical validity, which is not a narrowly syntactic feature (the one (1) shares not with (2), but with (3)). Instead, (2), given the expressive conventions of the formal language in which it is couched, conveys the existence of a semantic relation of anaphoric dependence of the second occurrence of ' $a$ ' on the latter, which in natural languages is sometimes expressed in the same way as in the formal language to which (2) belongs, but which, as (1) shows, can be expressed in different ways.

I have made this point with an example involving a reflexive pronoun as our anaphoric expression. There are strict linguistic constraints (articulated by principles A and B of Binding Theory) requiring that reflexives like 'itself' in (1) be interpreted as anaphoric relative to 'Hesperus', and foreclosing that repeating 'Hesperus' 
could have the same effect. ${ }^{2}$ However, the point can also be made by means of examples without this feature. Consider, for instance, (5):

(5) If Hesperus equals Phosphorus, then it is visible in the morning.

There is no linguistic requirement that 'it' in (5) be interpreted as anaphoric with respect to 'Hesperus'. It is rather a pragmatic matter whether, in a given utterance, it should be understood that way, or as anaphoric relative to 'Phosphorus' instead, or rather as referring to another, contextually specified object. Still, if the former is the case, given what I take to be an adequate conception of logical form (García-Carpintero 2004) there is no question but that (6) is a correct first-order formalization - one counting as valid the inference from (4) and (5) to 'Hesperus is visible in the morning':

(6) $\mathrm{a}=\mathrm{b} \rightarrow \mathrm{P}(\mathrm{a})$

The reason is (as I would put it, cf. García-Carpintero 2004) that what we formalize is a topic-neutral (a "logical constant", one might say) constituent of what is understood, independently of the means (syntactic, pragmatic or whatever) by means of which that understanding occurs. This topic-neutral component is the one expressing the relation of anaphoric dependence, which philosophers writing on the topic give different names, such as "internal" or "de jure" coreference. ${ }^{3}$ But NS misses this, and therefore the criterion for when two co-referential expression "count as the same name" does not al-

${ }^{2}$ In a real utterance of 'Hesperus equals Hesperus' (outside the rarefied realm of hackneyed philosophical examples), the second occurrence of 'Hesperus' is understood as not dependent on the first, even though the terms are, of course, presented as in fact co-referential. Perhaps, for instance, two different naming practices associated with the expression-type are assumed in the context, relative to which the identity is asserted: "(that) Hesperus is (that other) Hesperus". Perry (1988: 242n) appreciates this point; Schroeter (2007) also acknowledges it on p. 599, but she seems to think that there are "standard" contexts in which the sentence would be understood as having logical form (2). I take it that this only happens in philosophical contexts; in truly standard ones, (3) provides its correct formalization.

${ }^{3}$ Perry (1988) and Lawlor (2010) use the first, Schroeter (2007) and Pinillos (2011) the second. Fine (2007: 40, 68) speaks instead of objects "being represented as the same". 
low us to capture the relation of sameness of form that is required to properly account for validity.

It is easy to see that the issue I have discussed in the previous paragraphs is just a generalization of the one Frege poses at the beginning of "On Sense and Reference". The issue is this: we have precisely defined notions of logical validity, such as the Tarskian model-theoretic one presupposed above applying to arguments in formal languages like those including (2), (3) and (6). However, to the extent that they are compelling, this is because they offer good explications of a pretheoretical notion applying to arguments involving natural language sentences such as (1), (4) and (5), and, indeed, the thoughts they express. ${ }^{4}$ This is a pre-theoretical notion of logical validity, paradigmatically one that semantic theories (broadly conceived) are supposed to account for; it is a manifestly semantically relevant property, in the previously canvassed sense. ${ }^{5}$

Now, the Fregean picture is a class of such broadly semantic theories, and hence it is to be expected that Fregeans will want to invoke their proprietary theoretical notions for that purpose. Thus: logical validity is logical truth-preservation, and this requires preservation of reference of the sort illustrated by (2) and (6), i.e., the one captured in formal languages (but not, as we have seen, in natural language) in the way the criterion NS allows for. The Fregean will say that this common "sort" will ultimately consist in that the referent of one expression is understood to be determined by the same sense as the referent of the other.

As we have seen, the inference formalized as $F a \therefore F a$, in contrast to the one formalized as $F a \therefore F b$, is valid and non-enthymematic; the suggestion that it is enthymematic - i.e., that there is an implicit third identity premise identifying the referent of the subjects of the other two-would launch us into a regress (cf. Heck 2012:

\footnotetext{
${ }^{4}$ García-Carpintero (1993, 2003, 2004) substantiates this claim.

${ }^{5}$ Semantics narrowly conceived aims to explain the sort of issues about language acquisition, etc., that a Principle of Compositionality is intended to deal with, on the view that García-Carpintero (2012) articulates. As (5) suggests, it may well be that an adequate account of intuitive validity should go beyond the proprietary resources of this theoretical undertaking, allowing itself to use more "pragmatic" notions.
} 
154-5, and Recanati 2013: 47-50 for recent discussions, and references therein). The claim formalized as $a=a$, as opposed to the one formalized as $a=b$, is similarly valid. External co-reference is hence not sufficient for the relation that in formal languages is captured by identity of type ${ }^{6}$ Identity of type of the representational devicewhich is what NS provides as a condition - is not sufficient either, nor is it necessary, as the examples above show. What manifests the presence of the relation of de jure or internal co-reference is rather an epistemic property, certainly not easy to explain but clearly in the vicinity of the properties that Frege mentioned, ${ }^{7}$ which different writers have tried to capture in slightly different terms:

First, ... the co-reference strikes you as obvious in the sense that no calculation or reflection is required before you're willing to treat the two uses of 'Bush' as co-referential (contrast: ' $54=7+47$ '). Second, ... the co-reference strikes you as rationally incontrovertible: you couldn't imagine how it could turn out that Bush isn't Bush ... (Schroeter 2007: 600; cf. also Schroeter 2012: sec. 1.)

... a good test of when an object is represented as the same is in terms of whether one might sensibly raise the question of whether it is the same. An object is represented as the same in a piece of discourse only if no one who understands the discourse can sensibly raise the question of whether it is the same. (Fine 2007: 40)

Any competent speaker who fully understands [(5)] will know of the italicized occurrence that if they manage to refer, then they refer to the same thing. (Pinillos 2011: 305)

Acknowledging the relation identified by these epistemic criteriaobtaining between, say, 'it' and 'Hesperus' in (5) — does not require the acceptance of any Fregean tenets. To agree that such a relation obtains and stands in need of explanation requires only the minimal self-awareness involved in detecting data for semantic theorizing. It

${ }^{6}$ In fact, external co-reference is not necessary either, as shown by the cases of confusion discussed in the literature already referred to; cf., e.g., Schroeter 2007 and Lawlor 2010.

${ }^{7}$ Frege mentions apriority, but this is puzzling; he surely accepts that $9=3^{2}$ has the form $a=b$ (the two expressions have different senses), even though the identity is a priori. 
is just one more factor we have to reckon with in properly accounting for rational assessment and rationalizing explanations of our acts, including mental acts such as judging, deciding or inferring.

The clearest proof that such an acknowledgement does not beg any questions in favor of a Fregean picture is that one can pre-theoretically identify the relation in the way just suggested, and then go on to provide a non-Fregean account. Thus, for instance, although Heck's (2012) general outlook is sympathetic to Fregeanism, he summarizes his proposal — which essentially involves recognizing the sort of "formal" relations highlighted above - thus: "I have argued ... that the notion of sense is not needed for the solution to Frege's puzzle" (op. cit., 172). Fine (2007) provides an account in terms of "semantic (or, more generally, representational) requirements", stating facts "which belong to the semantics of a given language" (or to a theory of representational states) (op. cit., 50) - the class of facts to be predicted or explained by such theories. The account is supposed to be entirely compatible with a Millian picture, barring any role for Fregean senses. Pinillos (2011: 317-22) offers a similarly relational account in terms of a primitive relation of "p-linking", which he characterizes by means of four axioms. In support of Millianism, he offers an argument against any theory which purports to explain coreference by ascribing a common item to the coreferring terms, be it a Fregean sense, a mental file, or whatever; the argument depends on the fact that such theories would characterize de jure coreference as an equivalence relation, whereas, he argues, it is not transitive. ${ }^{8}$

The alternative to NS that I am suggesting appeals to what I named above the internal co-reference criterion, IC. On this alternative, we have identity of names (or, better, terms or referential expressions in general) in the required sense when one anaphoric depends on the other in the way we have highlighted, as established by criteria like the ones offered by Schroeter, Fine, and Pinillos I have quoted above. IC differs from NS, because it does not rely on identity of type plus external coreference. It does not assume, say, that Fregean senses are required for an adequate characterization of the data to be accounted for.

${ }^{8}$ I do not find the argument compelling; cf. the discussion by Recanati (2013: 104-12) and Goodsell (2014: 310). 
Of course, important philosophical questions remain to be answered. To me, a most interesting one is whether, in order to fully explain the anaphoric dependence relations that a proper presentation of Frege's puzzle must mention, we must appeal to Fregean senses. By a "full explanation" I mean the sort of first-personally intelligible account of our rational assessments and rationalizing explanations that Fregeans aspire to provide. In previous work (García-Carpintero 2000, 2018) I have defended a form of the Fregean picture that I take to be immune to Millian arguments. This proposal agrees with Millians that the content of the assertions made with (1) and (5), and of the attitudes they express, are just singular propositions individuated by the referents of the singular terms. I argue, however, that a full account of the relevant states/acts requires accompanying referencefixing acts of presupposing. Both Pinillos (2011: 308) and Goodsell (2014: 296-7) contend that we cannot account for anaphoric dependence in such terms. I believe that their arguments can be answered, and that here too the presuppositional account is in a position to vindicate the need for a full-fledged Fregean account. Equally important in this respect would be to deal with the objections presented by Schroeter (2012), also in the context of accounting for anaphoric dependencies, to the sort of "two-dimensional" account I envisage. However, these are tasks for another occasion.

\section{Questions for Iacona}

With this background, I now go back to Iacona's discussion, and to my goal of raising questions for him to clarify. He makes much of contrasting arguments involving names (cases 1-4, 46-7) with similar arguments with indexicals replacing them (cases 5-8, 48-9). This might be ok if one is confronting narrowly syntactic views like NS above, but we both agree they should be rejected. I think we agree that, in the case of both indexicals and proper names, reasonings involving expressions with the same shape may have to be rendered in adequate formalizations with different constants in formal languages; we disagree whether this applies to 'Paderewski' in Kripke's example, but we agree if different Paderewskis are really meant. We also agree in the other direction; items involving expressions with different shapes may in both cases (names and indexicals) be for- 
malized with one and the same constant ('I'/'you', 'Aristotle'/'The Stagirite' in some contexts, 48, 74-5). On the other hand, given his definition of 'intrinsic property' quoted at the outset, and what I said above about the de jure coreference relation, it should be obvious that I also reject intrinsicalism; for, when it comes to the cases that Iacona discusses (involving both names and indexicals), what counts as an adequate formalization depends on my view on contextual matters.

However, firstly, I don't see how it follows from this that I should go along with Iacona's rejection of (UT), given the way he states the distinction between the logical and the semantic roles of logical form. Certainly, like most contemporary semanticists, I think we need a distinction (due to Dummett and Lewis, later elaborated in great detail by others, see for instance Yalcin 2014, and further references there), between what is nowadays usually called semantic content (meaning ascribed by grammar to linguistic types) and assertoric content (meaning determined in context by semantic content plus required contextual elements). ${ }^{9}$ Features of natural language like systematicity or productivity that are supposed to be explained by compositionality depend on the former, while logical validity depends on the latter, because it is truth-preservation under certain constraints, and typically only assertoric contents get truth-values. But I suppose this is not enough to reject (UT), otherwise we wouldn't need Iacona's arguments based on his cases. Besides, assertoric contents, the way I have characterized them, crucially depend on semantic contents, which in my view provides support for some sort of unicity — or at least robust metaphysical connections - between the logical and the semantic notions of logical form.

This leads me to the second question or doubt I wanted to raise. As I said, the clearest disagreement I have with Iacona concerns issues of transparency. However, strictly speaking, there is no disagreement here either; for I agree with him that logical validity is not

${ }^{9}$ I have characterized semantic content as character content (García-Carpintero 2006). As Kratzer puts the same idea: "Words, phrases and sentences acquire content when we utter them on particular occasions. What that content is may differ from one context to the next. It is the task of semantics to describe all those features of the meaning of a linguistic expression that stay invariable in whatever context the expression may be used. This invariable element is the meaning proper of an expression" (Kratzer 2012: 4). 
a transparent matter, in Boghossian's sense. Although I haven't elaborated on this here, this is because I agree that cases like Boghossian's 'Pavarotti' (72) show that a rational thinker may fail to appreciate the validity of an argument, or wrongly judge valid an invalid one. ${ }^{10}$ However, I fail to see the need to take this as far as Iacona wantsto insist that 'Hesperus equals Phosphorus' is a valid claim (78-9). That view would be excluded by any account that acknowledges a logical and semantic role to relations of de jure coreference; and I fail to see in Iacona's discussion and distinctions any reason to put them aside. I have only found a passage in his discussion (p. 50) where he appears to tackle something like this issue. He considers there the "appeal to indexed syntactic items", which is the way anaphoric relations are represented in contemporary semantic theories. But the argument he provides there only shows that the relevant relation cannot be an "intrinsic" one in his sense, i.e., a context-independent one- - something with which I fully agree, as I made clear above. I thus cannot find any reason to disregard the significance of the expression of de jure coreference relations to these matters, and hence to accept Iacona's identification for present purposes of 'Hesperus equals Phosphorus' with 'Hesperus equals itself'. ${ }^{11}$

Manuel García-Carpintero LOGOS-BIAP, Departament de Filosofia University of Barcelona

\section{References}

Fiengo, R. and May, R. 2006. De Lingua Belief. Cambridge, Mass.: MIT Press. Fine, K. 2007. Semantic Relationism. Oxford: Blackwell. Fodor, J. 2008. LOT 2: The Language of Thought Revisited. Oxford: Oxford

\footnotetext{
${ }^{10}$ I take this to be compatible with the a priori character of logic, because, like most contemporary epistemologists, I take a priori justification to be (correctly) defeasible.

${ }^{11}$ Financial support for my work was provided by the DGI, Spanish Government, research projects FFI2016-80588-R and FFI2016-81858-REDC, and the award ICREA Academia for excellence in research, 2018, funded by the Generalitat de Catalunya. Thanks to Andrea Bianchi for his comments, and to Michael Maudsley for the grammatical revision.
} 
University Press.

García-Carpintero, M. 1993. The grounds for the model-theoretic account of the logical properties. Notre Dame Journal of Formal Logic 34: 107-31.

García-Carpintero, M. 2000. A presuppositional account of reference-fixing. Journal of Philosophy 97: 109-47.

García-Carpintero, M. 2003. Gómez-Torrente on modality and Tarskian logical consequence. Theoria 18(47): 159-70.

García-Carpintero, M. 2004. Logical form: syntax and semantics. In Wittgenstein Today, ed. by A. Coliva and E. Picardi. Padova: Il Poligrafo.

García-Carpintero, M. 2006. Recanati on the semantics/pragmatics distinction. Crítica 38: 35-68.

García-Carpintero, M. 2014. Understanding anaphoric dependence: a reply to Glezakos. Revista de Filosofía de la Universidad de Costa Rica 53(136): 119-24.

García-Carpintero, M. 2018. The Mill-Frege theory of proper names. Mind 127(508): 1107-68.

Goodsell, T. 2014. Is de jure coreference non-transitive? Philosophical Studies 167: 291-312.

Heck, R.G. Jr. 2012. Solving Frege's puzzle. Journal of Philosophy 109: 132-74.

Iacona, A 2018. Logical Form: Between Logic and Natural Language. Synthese Library. Cham: Springer.

Kratzer, A. 2012. Modals and Conditionals. Oxford: Oxford University Press.

Kripke, S. 1979. A puzzle about belief. In Meaning and Use, ed. by A. Margalit. Dordrecht: D. Reidel.

Lawlor, K. 2010. Varieties of coreference. Philosophy and Phenomenological Research 81: 485-95.

Perry, J. 1988. Cognitive significance and new theories of reference. Noûs 22: 1-18. Also in his The Problem of the Essential Indexical and other Essays. Oxford: Oxford University Press, 1993.

Pinillos, N. Á. 2011. Coreference and meaning. Philosophical Studies 154: $301-24$.

Pryor, J. 2017. De jure codesignation. In A Companion to the Philosophy of Language, ed. by B. Hale, C. Wright, and A. Miller. $2^{\text {nd }}$ ed. Oxford: Blackwell.

Recanati, F. 2013. Mental Files. Oxford: Oxford University Press.

Recanati, F. 2016: Mental Files in Flux. Oxford: Oxford University Press.

Sainsbury, M. and Tye, M. 2012. Seven Puzzles of Thought. Oxford: Oxford University Press.

Schroeter, L. 2012. Bootstrapping our way to samesaying. Synthese 189 (1): 177-97.

Schroeter, L. 2007. The illusion of transparency. Australasian Journal of Philosophy 85: 597-618.

Schroeter, L. and Schroeter, F. 2016. Semantic deference versus semantic coordination. American Philosophical Quarterly 53(2): 193-210.

Yalcin, S. 2014. Semantics and metasemantics in the context of generative grammar. In Metasemantics: New Essays on the Foundations of Meaning, ed. by A. Burgess and B. Sherman, Oxford: Oxford University Press. 